\title{
Essential oil variation in wild populations of Artemisia saharae (Asteraceae) from Tunisia: chemical composition, antibacterial and antioxidant properties
}

Sami Zouari ${ }^{1}$, Imen Ayadi ${ }^{2}$, Nahed Fakhfakh ${ }^{3}$, Hamida Jdir ${ }^{4}$, Latifa Aloui ${ }^{1}$, Mohamed Kossentini ${ }^{1}$, Ahmed Rebai ${ }^{2}$ and Nacim Zouari ${ }^{3,4^{*}}$

\begin{abstract}
Background: Artemisia saharae Pomel is a new taxon of Artemisia herba-alba Asso (Asteraceae) which is endemic to Tunisia and Algeria. This shrub, commonly known as white wormwood or desert wormwood, is largely used in folk medicine and as a culinary herb. The bulks aromatic plants come from wild populations whose essential oils compositions as well as their biological properties are severely affected by several factors such as geographic conditions. Therefore, the aim of the present work is to provide more information about the influence of altitude variation on the essential oil composition, antimicrobial and antioxidant properties of Artemisia saharae growing wild in the same geographical area.
\end{abstract}

Results: Essential oils were extracted by hydrodistillation of leaves and flowers of the plant collected from seven different altitudes of the Baten Zamour region (southwest of Tunisia). The highest essential oil yields (2.70-2.80\%) were obtained for populations of high altitudes.

Seventy-five compounds, representing 92.78 to $96.95 \%$ of the total essential oils, were separated and identified. Essential oils were characterized by very high percentage of oxygenated monoterpenes (52.1-72.6\%) which constituted the predominant class. From the analyzed populations, the major compounds (>7\%) were a-thujone, $\beta$-thujone, chrysanthenone, camphor, chrysanthenyl acetate, and sabinyl acetate. Sabinyl acetate which was detected in some populations at relatively high percentages (7.7-10.8\%) seems to be characteristic to Southern Tunisian A. saharae. The studied essential oil showed a chemical diversity depending on the population altitude as revealed by linear discriminant and cluster analyses.

Conclusions: Three population groups associated with altitudinal levels were distinguished. It is worthy to note that the most discriminating compounds of chemical groups were the minor ones. Despite the high variation of essential oil compositions, the high altitude population did not affect severely the antibacterial activity against the most tested strains. Altitude seems to be an important factor influencing the yield and the chemical profile of Artemisia saharae essential oils. Knowledge of the chemical composition of essential oils in relation to environmental factors is a very important quality criterion for their marketing and contributes to their valorization as functional ingredient in food technology.

Keywords: Artemisia saharae; White wormwood; Essential oil; Discriminant analysis; Antimicrobial activity; Antioxidant activity

\footnotetext{
* Correspondence: znacim2002@yahoo.fr

${ }^{3}$ Institut Supérieur de Biologie Appliquée de Médenine, Université de Gabès,

4119 Médenine, Tunisia

${ }^{4}$ Laboratoire de Biochime et de Génie Enzymatique des Lipases, Université

de Sfax, Ecole Nationale d'Ingénieurs de Sfax, B.P. 11733038 Sfax, Tunisia

Full list of author information is available at the end of the article
}

\section{实}

(c) 2014 Zouari et al.; licensee Springer. This is an Open Access article distributed under the terms of the Creative Commons Attribution License (http://creativecommons.org/licenses/by/4.0), which permits unrestricted use, distribution, and reproduction in any medium, provided the original work is properly credited. 


\section{Background}

In recent years, there has been a growing concern about the potentially adverse effects of chemical additives used in food industry and medicine. Therefore, there was a marked interest for natural products, considered to have very few side effects, as compared to synthetic chemicals. Consequently, the commercial development of medicinal plants and their derivatives, such as essential oils, as new sources of bioactive products to enhance human health and food preservation is of prime importance. Essential oils, formed by medicinal and aromatic plants as secondary metabolites, were very heterogeneous mixtures that may contain many compounds at different concentrations. However, several factors, namely climatic, geographic conditions, and ontogeny of collected plants may severely affect essential oil yield, their composition, and their biological properties. Thus, studies of chemical variability of essential oil in relation to environmental factors might provide information on what determines its chemical polymorphism. In addition, knowledge of the essential oils chemotypes is a very important quality criterion for their marketing and contributes to their commercialization as functional ingredients in food technology or in phytopharmacy (Zouari, 2013).

Recently, Le Floc'h et al. (2010) reported that Artemisia saharae Pomel is a new taxon of Artemisia herba-alba Asso (Asteraceae) which is endemic to Tunisia and Algeria. This shrub, commonly known as white wormwood or desert wormwood (Arabic name chih), was widely used in traditional medicine against diabetes, bronchitis, diarrhea, neuralgias, and hypertension (Tahraoui et al. 2007). The antioxidant, antihypertensive, antibacterial, antileshmanial, anthelmintic and antispasmodic activities of A. herba-alba essential oils have been reported (Yashphie et al. 1987; Hatimi et al. 2001; Zouari et al. 2010). Previous studies assessed on the composition variability of $A$. herba-alba essential oils have essentially considered the effect of the geographical locations and consequently different climatic conditions (Mighri et al. 2010; Belhattab et al. 2014). However, there is little information about the influence of altitude variation on the essential oil composition of $A$. herba-alba growing in the same geographical area. In fact, altitude is one of the abiotic stresses which is associated with alterations in a number of environmental factors (Kofidis et al. 2003).

In Baten Zamour region (Gafsa, southwest of Tunisia), A. saharae populations were found in different altitudes. Therefore, the aim of the present work is to provide more information on the chemical diversity of $A$. saharae volatiles collected from seven different altitudinal wild populations. The chemical variability of the essential oils among samples was assessed by linear discriminant analysis and UPGMA (unweighted pair-group method with averaging) cluster analysis. Besides, influence of altitude on yield, and antibacterial and antioxidant properties of essential oils was also assessed.

\section{Methods}

\section{Populations analyzed and sampling}

The seven populations of $A$. saharae Pomel (= A. herbaalba Asso) collected from the same locality and from different altitudes were reported in Table 1 . Five individuals $(n=5)$ from each population were sampled over the entire population area the flowering stage (November 2012). The distance between individuals exceeded $20 \mathrm{~m}$, to avoid collection from close parents. After that, the fresh vegetable matter was dried in the shade, until constancy of the mass (20 days). Separated from stems, aerials parts were subjected for essential oil extraction.

\section{Essential oil extraction}

The dry matter was submitted to hydrodistillation for $4 \mathrm{~h}$, using a Clevenger-type apparatus. Each essential oil was dried over anhydrous sodium sulphate and stored in sealed vials protected from light at $-20^{\circ} \mathrm{C}$ until analysis.

\section{Essential oil analyses \\ Gas chromatography (GC)}

A Hewlett-Packard 5890 series II gas chromatograph equipped with HP-5MS capillary column $30 \mathrm{~m} \times 0.25 \mathrm{~mm}$ i.d., film thickness $0.25 \mu \mathrm{m}$; Hewlett-Packard) and connected to a flame ionization detector (FID) was used. The column temperature was programmed at $50^{\circ} \mathrm{C}$ for $1 \mathrm{~min}$, then $7^{\circ} \mathrm{C} / \mathrm{min}$ to $250^{\circ} \mathrm{C}$, and then left at $250^{\circ} \mathrm{C}$ for $5 \mathrm{~min}$. The injection port temperature was $240^{\circ} \mathrm{C}$ and that of the detector $250^{\circ} \mathrm{C}$ (split ratio: $1 / 60$ ). The carrier gas was helium (99.995\% purity) with a flow rate of $1.2 \mathrm{ml} / \mathrm{min}$ and the analysed sample volume was $2 \mu \mathrm{l}$. Percentages of the constituents were calculated by electronic integration of FID peak areas, without the use of response factor correction. Mean percentage of compounds in A. herba-alba essential oils represented the average calculated on five individuals $(n=5)$. Retention indices (RI) were calculated for separate compounds relative to $\left(C_{7}-C_{25}\right)$ n-alkanes

\section{Table 1 Location of the analyzed populations of} A. herba-alba

\begin{tabular}{llll}
\hline Population $^{\text {a }}$ & Latitude & Longitude & Altitude (m) \\
\hline 1 & $34^{\circ} 21^{\prime} 03^{\prime \prime} \mathrm{N}$ & $009^{\circ} 23^{\prime} 31^{\prime \prime} \mathrm{E}$ & 194 \\
2 & $34^{\circ} 20^{\prime} 58^{\prime \prime} \mathrm{N}$ & $009^{\circ} 23^{\prime} 30^{\prime \prime} \mathrm{E}$ & 206 \\
3 & $34^{\circ} 20^{\prime} 55^{\prime \prime} \mathrm{N}$ & $009^{\circ} 23^{\prime} 30^{\prime \prime} \mathrm{E}$ & 219 \\
4 & $34^{\circ} 20^{\prime} 53^{\prime \prime} \mathrm{N}$ & $009^{\circ} 23^{\prime} 31^{\prime \prime} \mathrm{E}$ & 230 \\
5 & $34^{\circ} 20^{\prime} 51^{\prime \prime} \mathrm{N}$ & $009^{\circ} 23^{\prime} 30^{\prime \prime} \mathrm{E}$ & 240 \\
6 & $34^{\circ} 21^{\prime} 59^{\prime \prime} \mathrm{N}$ & $009^{\circ} 12^{\prime} 55^{\prime \prime} \mathrm{E}$ & 361 \\
7 & $34^{\circ} 24^{\prime} 41^{\prime \prime} \mathrm{N}$ & $009^{\circ} 13^{\prime} 31^{\prime \prime} \mathrm{E}$ & 841 \\
\hline
\end{tabular}

${ }^{\mathrm{a}}$ The numbering refers to the $A$. herba-alba populations. 
mixture (Aldrich Library of Chemicals Standards) (Kovàts 1958).

\section{Gas chromatography/Mass spectrometry (GC/MS)}

The isolated volatile compounds were analysed by GC/MS, using an Agilent Technologies $6890 \mathrm{~N}$ gas chromatograph. The fused HP-5MS capillary column (the same as that used in the GC/FID analysis) was coupled to an Agilent Technologies 5973B mass-spectrometer (Hewlett-Packard, Palo Alto, CA, USA). The oven temperature was programmed at $50^{\circ} \mathrm{C}$ for $1 \mathrm{~min}$, then $7^{\circ} \mathrm{C} / \mathrm{min}$ to $250^{\circ} \mathrm{C}$, and then left at $250^{\circ} \mathrm{C}$ for $5 \mathrm{~min}$. The injection port temperature was $250^{\circ} \mathrm{C}$ and that of the detector was $280^{\circ} \mathrm{C}$ (split ratio: $1 / 100$ ). The carrier gas was helium (99.995\% purity) with a flow rate of $1.2 \mathrm{ml} / \mathrm{min}$. The mass spectrometer conditions were as follow: ionization voltage, $70 \mathrm{eV}$; ion source temperature, $150^{\circ} \mathrm{C}$; electron ionization mass spectra were acquired over the mass range $50-550 \mathrm{~m} / \mathrm{z}$.

\section{Volatile compounds identification}

The essential oil compounds of $A$. herba-alba were identified by comparing the mass spectra data with spectra available from the Wiley 275 mass spectra libraries (software, D.03.00). Further identification confirmations were made referring to retention indices (RI) data generated from a series of known standards of n-alkanes mixture $\left(C_{7}-C_{25}\right)$ (Kovàts 1958) and to those previously reported in the literature (Adams 2001; Zouari et al. 2010).

\section{Antioxidant activities}

The metal $\left(\mathrm{Fe}^{2+}\right)$ chelating and DPPH radical-scavenging activities of essential oils were measured as previously described (Dinis et al. 1994; Kirby and Schmidt 1997). Metal $\left(\mathrm{Fe}^{2+}\right)$ chelating activity was presented by $\mathrm{IC}_{50}$ values, defined as the concentration of the extract needed to chelate $50 \%$ of $\mathrm{Fe}^{2+}$ present in the test solution. Therefore, $\mathrm{IC}_{50}$ values were calculated from the graph of chelating percentages against extract concentration. Lower $\mathrm{IC}_{50}$ values reflected better chelating activity. Ethylenediaminetetraacetic acid (EDTA) and butylhydroxyanisole (BHA) were used as positive controls for metal $\left(\mathrm{Fe}^{2+}\right)$ chelating and DPPH radical-scavenging activities, respectively.

\section{Antibacterial activity Bacterial strains}

Antibacterial activities of $A$. herba-alba essential oils were tested against 6 strains of bacteria: three Gram-negative (Escherichia coli, Klebsiella pneumoniae, and Salmonella typhimurium) and three Gram-positive (Bacillus cereus, Enterococcus faecalis, and Micrococcus luteus). Microorganisms were obtained from the culture collection of the Laboratory of Enzyme Engineering and Microbiology ("Ecole Nationale d'Ingénieurs de Sfax", Tunisia).

\section{Determination of the minimum inhibitory concentration} (MIC)

MICs values, which represented the lowest essential oil concentration that preventing visible growth of microorganisms, were determined as previously described (Ben Bnina et al. 2009). All tests were performed in MuellerHinton broth (MHB) supplemented with 5\% dimethylsulfoxide (DMSO). Bacterial strains were cultured overnight in $\mathrm{MHB}$ medium at $37^{\circ} \mathrm{C}$. Tubes of MHB containing various concentrations of essential oils were inoculated with $10 \mu$ bacterial inoculums adjusted to $10^{6} \mathrm{cfu} / \mathrm{ml}$ of bacteria cells. Then, they were incubated under shaking conditions $(200 \mathrm{rpm})$ for $24 \mathrm{~h}$ at $37^{\circ} \mathrm{C}$. Control tubes without tested samples were essayed simultaneously. All tests were carried out for five sample replications and the results were averaged.

\section{Statistical analyses}

The distribution of the 75 compounds identified from the essential oil was checked by a descriptive statistical analysis using the SPSS software for Windows ${ }^{\text {Tx }}$ (version 17, SPSS Inc., Chicago, IL, USA). The percentages of compounds were transformed using the arcsine transformation in order to improve the distribution property. However, this transformation did not yield satisfactory results for 18 variables. Therefore, for compounds having skewed distributions, a non parametric one-way analysis of variance KruskalWallis test (SPSS software, 17.0) was performed. The chemical population structure assessed by Linear Discriminant Analysis (LDA) and dendrogram analysis were performed as previously described (Zouari et al. 2012). Duncan's multiple range test $(p<0.05)$ was used to compare the averages of essential oil yields and the metal $\left(\mathrm{Fe}^{2+}\right)$ chelating and the DPPH radical-scavenging activities among populations. Correlation and the covariance analysis between the MICs values of strains and the populations' altitudes were performed using the SPSS software 17.0.

\section{Results and discussion}

Chemical variability of essential oils according to population altitude

Seven wild populations of $A$. herba-alba were collected during the flowering phase and from different altitudes which ranged from $194 \mathrm{~m}$ (population 1) to $841 \mathrm{~m}$ (population 7) (Table 1). The analyzed populations were located in the same region (Baten Zamour, south west of Tunisia) with an inferior arid climate characterized by an average annual rainfall of $150 \mathrm{~mm} /$ year. The chemical composition of essential oils was investigated using both GC/FID and GC/MS techniques. The percentages and the retention indices of the identified compounds of these essential oils were listed in Table 2 in the order of their elution on the HP-5MS column. Seventy-five compounds, representing 92.0 to $96.7 \%$ of the total essential 
Table 2 Mean percentage of compounds (\%) in A. herba-alba essential oils

\begin{tabular}{|c|c|c|c|c|c|c|c|c|c|c|c|}
\hline $\mathrm{No}^{\mathrm{a}}$ & Compounds & $\mathrm{RI}^{\mathbf{b}}$ & $1^{c}$ & $2^{c}$ & $3^{c}$ & $4^{c}$ & $5^{c}$ & $6^{c}$ & $7^{c}$ & $p_{1}$ Fisher test & $p_{2}$ Kruskal- Wallis test \\
\hline 1 & cis-Salvene & 848 & 0.1 & & & & & 0.1 & 0.1 & na & ns \\
\hline 2 & Tricyclene & 919 & 0.3 & & 0.1 & 0.1 & 0.1 & 0.1 & 0.1 & ns & ns \\
\hline 3 & a-Thujene & 924 & 0.2 & 0.4 & 0.6 & & & 0.1 & 0.1 & na & ns \\
\hline 4 & a-Pinene & 930 & 1.6 & 1.9 & 3.2 & 1.9 & 2.7 & 1.4 & 1.7 & ns & ns \\
\hline 5 & Camphene ${ }^{e}$ & 946 & 2.8 & 0.4 & 0.8 & 0.8 & 0.8 & 0.5 & 0.9 & * & ns \\
\hline 6 & Verbenene & 950 & 0.3 & 0.3 & 0.3 & 0.2 & 0.3 & 0.2 & 0.4 & ns & ns \\
\hline 7 & 2(5H)-Furanone, 5,5-dimethyl- & 952 & & & & & & & 0.1 & na & ns \\
\hline 8 & Sabinene & 970 & 1.2 & 0.6 & 0.3 & 0.3 & 0.3 & 0.9 & 0.7 & ns & ns \\
\hline 9 & 3-Octenol & 972 & & & 0.2 & & & & & na & ns \\
\hline 10 & $\beta$-Pinene $e^{e}$ & 973 & 0.3 & & 0.1 & & 0.1 & & 0.1 & na & * \\
\hline 11 & Myrcene ${ }^{e}$ & 986 & 0.2 & 0.4 & 0.5 & 0.5 & 0.4 & 0.6 & 0.9 & * & * \\
\hline 12 & Benzene,1,2,4-trimethyl- & 990 & 0.3 & 0.3 & 0.4 & 0.8 & 0.3 & 0.4 & 0.6 & ns & ns \\
\hline 13 & a-Phellandrene & 1000 & & & 0.1 & 0.1 & 0.1 & 0.1 & 0.1 & na & ns \\
\hline 14 & o-Isopropenyltoluene & 1009 & 0.1 & 0.1 & 0.3 & 0.2 & 0.1 & 0.1 & 0.1 & ns & ns \\
\hline 15 & a-Terpinene & 1013 & 0.1 & 0.2 & 0.1 & 0.1 & 0.2 & 0.3 & 0.3 & ns & ns \\
\hline 16 & p-Cymene $e^{e}$ & 1021 & 2.6 & 1.3 & 1.3 & 1.8 & 1.5 & 1.6 & 2.1 & ns & * \\
\hline 17 & 1,8-Cineole & 1028 & 4.1 & 2.5 & 1.6 & 2.3 & 3.5 & 1.5 & 1.9 & ns & ns \\
\hline 18 & $\gamma$-Vinyl- $\gamma$-valerolactone & 1038 & 0.2 & 0.1 & 0.1 & 0.2 & 0.2 & 0.2 & 0.4 & ns & ns \\
\hline 19 & cis-Arbusculone & 1049 & 0.7 & 3.2 & 3.0 & 2.2 & 3.0 & 1.6 & 2.8 & ns & ns \\
\hline 20 & Y-Terpinene & 1055 & 0.2 & 0.4 & 0.2 & 0.3 & 0.3 & 0.4 & 0.5 & ns & ns \\
\hline 21 & trans-Arbusculone & 1067 & 0.6 & 2.4 & 2.1 & 1.6 & 2.1 & 1.3 & 2.2 & ns & ns \\
\hline 22 & Terpinolene & 1085 & 0.1 & 0.2 & 0.3 & 0.3 & 0.3 & 0.2 & 0.3 & ns & ns \\
\hline 23 & Linalool & 1095 & & 0.1 & 0.1 & 0.2 & 0.1 & & 0.1 & na & ns \\
\hline 24 & Filifolone & 1101 & 1.2 & 1.0 & 2.2 & 2.4 & 1.9 & 1.0 & 1.6 & ns & ns \\
\hline 25 & $a-$ Thujone $^{d}$ & 1102 & 13.0 & 11.4 & 0.5 & 2.1 & 2.6 & 20.2 & 8.2 & ns & ns \\
\hline 26 & $\beta$-Thujone ${ }^{d}$ & 1117 & 9.2 & 4.7 & 1.3 & 1.9 & 2.7 & 9.9 & 3.5 & ns & ns \\
\hline 27 & cis-2-p-Menthen-1-ol & 1119 & & 0.1 & & & & & & na & ns \\
\hline 28 & Chrysanthenone $^{d}$ & 1124 & 4.7 & 7.7 & 14.0 & 14.0 & 9.9 & 8.3 & 10.9 & ns & ns \\
\hline 29 & trans-2-p-Menthen-1-ol & 1135 & & 0.1 & & & & & & na & ns \\
\hline 30 & 1-Terpineol & 1138 & 0.7 & 1.5 & & 0.8 & & 0.1 & 0.1 & na & ns \\
\hline 31 & Pinocarveol $^{e}$ & 1139 & & 1.0 & 5.8 & 2.7 & 4.3 & 3.0 & 3.1 & $* * *$ & $* *$ \\
\hline 32 & Camphor ${ }^{\mathrm{d}, \mathrm{e}}$ & 1147 & 10.7 & 0.7 & 1.2 & 0.4 & 0.7 & 0.6 & 3.4 & $* *$ & $* *$ \\
\hline 33 & Sabina ketone & 1158 & 0.3 & 0.1 & 1.9 & 1.0 & 1.2 & 0.8 & 0.4 & ns & ns \\
\hline 34 & Pinocarvone & 1163 & 1.3 & 1.2 & 1.1 & 0.9 & 1.3 & 0.3 & 1.2 & ns & ns \\
\hline 35 & Borneol & 1167 & 1.4 & 0.5 & 0.8 & 0.6 & 0.7 & 0.4 & 0.8 & ns & ns \\
\hline 36 & 4-Terpineol & 1177 & 1.5 & 0.9 & 0.7 & 0.6 & 0.8 & 1.0 & 1.0 & ns & ns \\
\hline 37 & p-Cymen-8-ol & 1183 & 0.4 & 0.2 & 0.4 & 0.3 & 0.3 & 0.3 & 0.4 & ns & ns \\
\hline 38 & $a_{\text {-Terpineol }}{ }^{e}$ & 1189 & 0.3 & 0.1 & & & & & & na & * \\
\hline 39 & Myrtenol & 1194 & 0.4 & 0.2 & 0.5 & 0.1 & 0.4 & 0.5 & 0.5 & ns & ns \\
\hline 40 & Verbenone & 1208 & 0.3 & 0.4 & 0.6 & 0.8 & 0.4 & 0.4 & 0.8 & ns & ns \\
\hline 41 & Carveol & 1217 & & 0.2 & 0.2 & 0.3 & 0.2 & 0.3 & 0.2 & ns & ns \\
\hline 42 & Nordavanone & 1225 & 0.7 & 0.5 & 0.1 & 1.4 & 0.4 & 0.2 & 0.4 & ns & ns \\
\hline 43 & Cuminal & 1237 & 0.4 & 0.2 & 0.1 & 0.1 & 0.2 & 0.3 & 0.3 & ns & ns \\
\hline
\end{tabular}


Table 2 Mean percentage of compounds (\%) in A. herba-alba essential oils (Continued)

\begin{tabular}{|c|c|c|c|c|c|c|c|c|c|c|c|}
\hline 44 & Piperitone & 1252 & 0.3 & 0.3 & 0.4 & 0.3 & 0.2 & 0.6 & 0.5 & ns & ns \\
\hline 45 & Chrysanthenyl acetate $e^{\mathrm{d}, \mathrm{e}}$ & 1257 & 10.2 & 7.9 & 21.1 & 11.5 & 18.7 & 9.1 & 8.2 & * & * \\
\hline 46 & Isopiperitenone & 1270 & 0.4 & 0.2 & 0.3 & 0.5 & 0.3 & 0.2 & 0.4 & ns & ns \\
\hline 47 & Bornyl acetate & 1281 & 1.4 & 0.2 & 0.4 & 0.2 & 0.5 & 0.2 & 0.5 & ns & ns \\
\hline 48 & Sabinyl acetate $^{d}$ & 1290 & 7.7 & 10.8 & 2.8 & 4.0 & 6.2 & 10.3 & 10.6 & ns & ns \\
\hline 49 & Thymol & 1301 & 0.5 & 0.3 & 0.6 & 0.4 & 0.3 & 0.6 & 0.6 & ns & ns \\
\hline 50 & Myrtenyl acetate & 1318 & 0.7 & 0.6 & 0.7 & 1.2 & 0.9 & 1.1 & 1.9 & ns & ns \\
\hline 51 & Piperitenone & 1344 & 0.1 & 0.6 & 0.1 & 0.7 & 0.2 & 0.6 & 1.0 & ns & ns \\
\hline 52 & Norchrysanthemic acid methyl ester & 1359 & 0.5 & 1.1 & 2.6 & 2.8 & 2.0 & 1.9 & 2.0 & ns & ns \\
\hline 53 & a-Copaene & 1372 & 2.4 & 0.4 & 0.4 & 0.2 & 0.2 & 0.4 & 0.7 & ns & ns \\
\hline 54 & Methyl cinnamate & 1379 & & & & & & & 0.3 & na & ns \\
\hline 55 & cis-Jasmone & 1395 & 3.5 & 3.4 & 2.9 & 3.3 & 2.2 & 2.2 & 2.8 & ns & ns \\
\hline 56 & Davana furan & 1399 & & 0.1 & & 0.2 & 0.1 & 0.1 & 0.1 & na & ns \\
\hline 57 & $\beta$-Caryophyllene & 1417 & 0.2 & 0.4 & 0.4 & 0.3 & 0.5 & 0.1 & 0.4 & ns & ns \\
\hline 58 & p-Nitroanisole & 1450 & 0.2 & 1.2 & 1.5 & 1.9 & 1.1 & 0.4 & 0.9 & ns & ns \\
\hline 59 & Aromadendrene & 1458 & 0.2 & 1.1 & 0.5 & 1.5 & 0.8 & 0.5 & 0.6 & ns & ns \\
\hline 60 & a-Amorphene & 1472 & 0.2 & 0.2 & 0.2 & 0.6 & 0.6 & 0.3 & 0.4 & ns & ns \\
\hline 61 & Germacrene-De & 1478 & 0.8 & 2.2 & 1.4 & 2.4 & 2.2 & 1.8 & 1.4 & $* *$ & $*$ \\
\hline 62 & Bicyclogermacrene $e^{e}$ & 1493 & 0.4 & 1.7 & 0.7 & 1.3 & 1.1 & 0.9 & 0.9 & $* * *$ & * \\
\hline 63 & Davana ether (isomer) ${ }^{e}$ & 1496 & 0.1 & 1.0 & 0.6 & 1.5 & 1.0 & 0.4 & 0.4 & $* *$ & * \\
\hline 64 & Davana ether (isomer) ${ }^{\mathrm{e}}$ & 1504 & 0.2 & 2.5 & 0.7 & 3.4 & 2.1 & 0.9 & 0.7 & * & * \\
\hline 65 & Davana ether (isomer) & 1514 & & 0.9 & 1.2 & 0.9 & 0.6 & 0.3 & 0.2 & na & ns \\
\hline 66 & $\delta$-Cadinene & 1518 & 0.2 & 0.4 & & 0.4 & 0.6 & 0.2 & 0.1 & ns & ns \\
\hline 67 & Nerolidol & 1556 & 0.4 & 0.2 & & 0.1 & 0.4 & 0.1 & 0.3 & na & ns \\
\hline 68 & Palustrol & 1567 & & 0.2 & 0.1 & & & & & na & ns \\
\hline 69 & Spathulenol $^{\mathrm{e}}$ & 1579 & 2.4 & 3.0 & 3.4 & 3.0 & 3.0 & 1.6 & 1.8 & * & $*$ \\
\hline 70 & Caryophyllene oxide & 1588 & 0.4 & 0.9 & 1.1 & 0.8 & 0.9 & 0.4 & 0.7 & ns & ns \\
\hline 71 & Viridiflorol & 1593 & 0.2 & 1.0 & 0.3 & 0.4 & 0.2 & & 0.1 & na & ns \\
\hline 72 & cis-Davanone $^{\mathrm{e}}$ & 1608 & 0.3 & 1.3 & 2.1 & 1.2 & 2.6 & 0.7 & 2.8 & $* *$ & $* *$ \\
\hline 73 & $\left.\right|_{\text {sospathulenol }} ^{e}$ & 1637 & 0.2 & 1.7 & 1.2 & 1.4 & 1.3 & 0.5 & 1.1 & $* *$ & * \\
\hline 74 & t-Cadinol & 1653 & 0.1 & 0.3 & & 0.3 & & 0.1 & & na & ns \\
\hline \multirow[t]{8}{*}{75} & Vulgarol Be & 1688 & & 0.8 & & 1.0 & 0.6 & 0.3 & 0.3 & $* * *$ & $* *$ \\
\hline & Total identified (\%) & & 96.7 & 94.4 & 94.8 & 92.0 & 95.8 & 96.0 & 96.0 & & \\
\hline & \multicolumn{11}{|l|}{ Grouped components (\%) } \\
\hline & Monoterpene hydrocarbons & & 10.0 & 6.2 & 8.3 & 6.6 & 7.1 & 6.5 & 8.2 & & \\
\hline & Oxygenated monoterpenes & & 71.3 & 56.6 & 60.2 & 52.1 & 59.2 & 72.6 & 64.0 & & \\
\hline & Sesquiterpene hydrocarbons & & 4.3 & 6.1 & 3.5 & 6.3 & 5.4 & 4.0 & 4.5 & & \\
\hline & Oxygenated sesquiterpenes & & 4.4 & 14.2 & 10.6 & 14.5 & 13.3 & 5.5 & 8.3 & & \\
\hline & Others & & 6.7 & 11.3 & 12.2 & 12.5 & 10.8 & 7.4 & 11.0 & & \\
\hline
\end{tabular}

${ }^{a}$ The numbering refers to elution order of compounds from a HP-5MS column and their percentages were obtained by FID peak-area normalization. The percentage for each population represents the average calculated on five individuals $(n=5)$. ${ }^{b} \mathrm{RI}$, retention indices calculated against $C_{7}-C_{25} n-a l k a n e s$ mixture on the HP-5MS column. ${ }^{\mathrm{C}}$ For the detailed description of the populations (1-7) locations, see Table $1 .{ }^{\mathrm{d}}$ Major compound in bold fond. ${ }^{\mathrm{e}}$ Compounds with a statistically significant variation among altitudinal populations. $p_{1}$ : $p$-values using Fisher test (one-way analysis of variance) applied for normally distributed variables. Fisher test was not applicable (na) for non-Normal distributed variables. $p_{2}: p$-values using non-parametric Kruskal-Wallis test (one-way analysis of variance). $p_{1}$ or $p_{2}$ are extremely significant (***) at $p \leq 0.001$, highly significant $(* *)$ at $0.001 \leq p \leq 0.01$, significant $(*)$ at $0.01 \leq p \leq 0.05$ and not significant (ns) at $p>0.05$. 
oils, were identified and separated on the basis of their chemical structures into 5 classes (Table 2). Haouari and Ferchichi (2009) identified one hundred compounds in essential oils of subcultured A. herba-alba originated from different localities in sub-arid to Saharan domains of Tunisia. By contrast, the present study showed that twenty two compounds were not previously reported by Haouari and Ferchichi (2009) which strengthen the idea of the large chemical polymorphism of A. herba-alba essential oils. Whatever the altitude level, all these essential oils were characterized by very high percentage of monoterpenes (58.7-81.3\%) and especially the oxygenated ones (52.1-72.6\%) which constituted the predominant class as was found previously for $A$. herba-alba essential oils (Boukrich et al. 2010; Zouari et al. 2010). The sesquiterpenes were also represented mainly by oxygenated sesquiterpenes (4.4-14.5\%). Nevertheless, Haouari and Ferchichi (2009) identified some populations of A. herba-alba from Southern Tunisia, where sesquiterpenes were more abundant than monoterpenes.

Results showed that Fisher test was not applicable for 18 essential oil compounds (non-Normal distributed variables) $\left(P_{1}\right.$, Table 2$)$. Therefore, for these compounds having skewed distributions, a non parametric one-way analysis of variance Kruskal-Wallis test was performed $\left(P_{2}\right.$, Table 2). By combining the two tests, the analysis of variance showed that altitude presented a significant effect on the variation of the concentration of 16 over 75 compounds. Table 2 also showed that the major compounds $(>7 \%)$ were $\alpha$-thujone $25, \beta$-thujone 26 , chrysanthenone 28, camphor 32, chrysanthenyl acetate 45 , and sabinyl acetate 48. However, they could not be considered as major compounds in all altitudinal populations. Results showed that chrysanthenone 28 (7.7-14.0\%) and chrysanthenyl acetate 45 (7.9-21.1\%) were highly represented in most populations. $\alpha$-Thujone 25 (8.2-20.2\%) and sabinyl acetate 48 (7.7-10.8\%) characterized four populations. $\beta$-Thujone 26 characterized population 1 (9.2\%) and population 6 (9.9\%). Whereas, camphor 32 (10.7\%) characterized only population 1 . Furthermore, when taking into account $\alpha$-thujone 25 and $\beta$-thujone 26, essential oils of populations 1 and 6 were dominated by thujones which ranged from 22.20 to $30.1 \%$. Previous works on $A$. herbaalba showed an important intraspecific chemical polymorphism of the essential oils among samples belonging to different geographical regions and climatic conditions. In fact, with a tremendous variability, $\alpha$-thujone (not detected-80\%), $\beta$-thujone (not detected-58\%), chrysanthenone (not detected-65\%), camphor (not detected-70\%), and 1,8-cineole (not detected-28\%) were reported in most studies from all the countries, where $A$. herba-alba grows. In addition, with a more restricted occurrence, davanone (not detected-51\%) and cis-chrysanthenyl acetate (not detected-69\%) showed high variability in A. herba-alba from
Spain and Tunisia (Belhattab et al. 2014). Usually one of these seven compounds or some of them in different proportions, dominated A. herba-alba essential oils, which is in agreement with the results obtained for populations 3 , 4 and 5 (Table 2). However, essential oils of populations 1 , 2,6 , and 7 contained sabinyl acetate $\mathbf{4 8}$ at relatively high percentages (7.7-10.8\%) seems to be characteristic to Southern Tunisian A. herba-alba as previously described (Haouari and Ferchichi 2009; Boukrich et al. 2010; Zouari et al. 2010).

Although all the essential oils analyzed in the present study could be classified as oxygenated monoterpene-rich oils, they showed wide range of variation in all their compounds. Therefore, the chemical differentiation among populations assessed by linear discriminant and cluster analyses was carried out.

\section{Chemical clusters among altitudinal populations}

To identify possible relationships between volatile compounds and altitudinal populations, linear discriminant analysis (LDA) was applied (Figure 1). The LDA, performed on average contents of all compounds for each population showed that the first two principal axes represented 96.30\% of the total variation. Moreover, principal axes of Figure 1 showed that essentially minor compounds played an important role to discriminate between individuals. The plot of the projection of the values of all the compounds onto the first two principal axes revealed 3 population groups associated with altitudinal levels (Figure 1). The first group, represented by population 1 (194 $\mathrm{m}$ altitude), was situated at the periphery of the plot. The second group, represented by populations 2 and 3 (206-219 m altitude), was situated in the centre of axes 1 and 2 at their negative sides. While, the third group represented by populations $4,5,6$, and 7 (230-841 m altitude), was situated at the positive side of axis 1.

In addition to the linear discriminant analysis and to better characterize populations groups, cluster analysis (dendrogram) was applied to a matrix linking essential oil composition to altitude population (Figure 2). The dendrogram generated from the Euclidean distances performed on the essential oils compounds of $A$. herbaalba populations showed population groupings globally similar to those observed by the LDA clustering. Figure 2 showed that the studied populations, which were geographically close populations, were separated in three main clusters. The first and the second groups were represented by populations 1 and 2, respectively. While, the third cluster was represented by populations 3, 4, 5, 6, and 7 (Figure 2).

In the case of the genus Artemisia, the altitudinal variation of the volatile compounds of some Artemisia species was previously studied. Haider et al. (2010) reported the essential oil composition of Artemisia nilagirica growing at different altitudes in Himachal Pradesh from India. The 


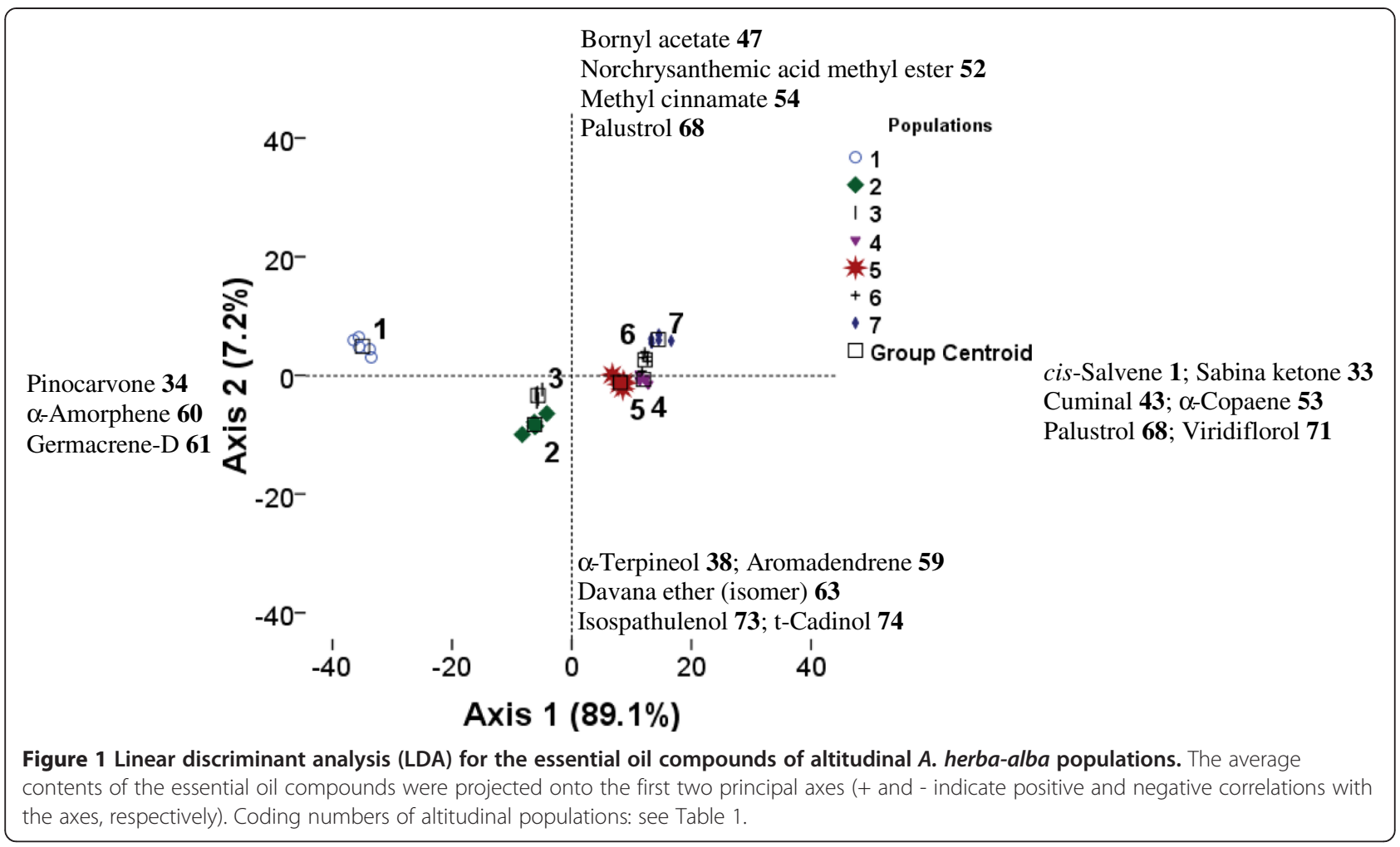

major compounds of the analyzed essential oils showed important variation with changes in altitude. At lower, middle, and higher altitudes, the major compounds were caryophyllene oxide (28.6\%), borneol (35.8\%), and camphor (46.9\%), respectively (Haider et al. 2010).

Influence of population altitude on yield, metal $\left(\mathrm{Fe}^{2+}\right)$ chelating and DPPH radical-scavenging activities of essential oils

The essential oils were extracted by hydrodistillation from the dried aerial parts of A. herba-alba collected during the flowering stage and their yields ranged from 1.30 to $2.80 \%(\mathrm{v} / \mathrm{w})$ (Table 3). These yields were higher in populations of high altitudes (populations 6 and 7) with a maximum obtained in the population 6 located at $361 \mathrm{~m}$. Nevertheless, it was reported that the lowest yield of Artemisia roxburghiana essential oil was obtained from plants collected at higher altitudes (Haider et al. 2009). It was also reported that Thymus praecox growing in higher altitudes contained lower essential oil than those grown in lower altitudes (Avci 2011). The altitude, the edapho-climatic conditions, as well as

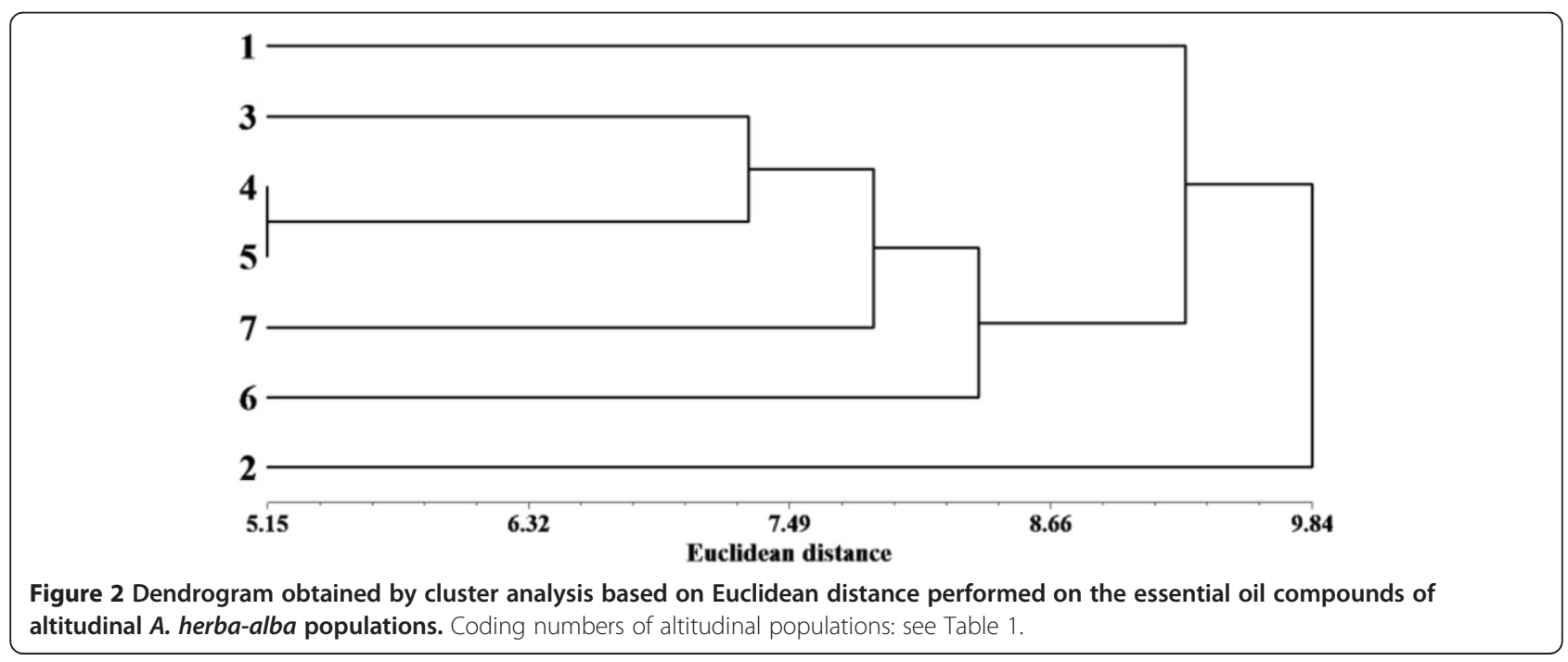


Table 3 Yield, and scavenging and chelating activities of A. herba-alba essential oils

\begin{tabular}{llll}
\hline Populations & Oil yield & Scavenging activity & Chelating activity \\
\hline 1 & $2.42 \pm 0.01^{\mathrm{bc}}$ & $10.60 \pm 2.56^{\mathrm{a}}$ & $0.28 \pm 0.12^{\mathrm{ab}}$ \\
2 & $1.73 \pm 0.43^{\mathrm{ab}}$ & $13.80 \pm 4.99^{\mathrm{a}}$ & $0.47 \pm 0.13^{\mathrm{bc}}$ \\
3 & $1.44 \pm 0.10^{\mathrm{a}}$ & $10.42 \pm 2.22^{\mathrm{a}}$ & $0.14 \pm 0.01^{\mathrm{a}}$ \\
4 & $1.36 \pm 0.17^{\mathrm{a}}$ & $15.30 \pm 3.60^{\mathrm{a}}$ & $0.75 \pm 0.13^{\mathrm{d}}$ \\
5 & $1.30 \pm 0.18^{\mathrm{a}}$ & $15.46 \pm 4.02^{\mathrm{a}}$ & $0.67 \pm 0.08^{\mathrm{cd}}$ \\
6 & $2.79 \pm 0.69^{\mathrm{c}}$ & $11.74 \pm 2.58^{\mathrm{a}}$ & $0.66 \pm 0.21^{\mathrm{cd}}$ \\
7 & $2.67 \pm 0.80^{\mathrm{c}}$ & $9.76 \pm 2.68^{\mathrm{a}}$ & $0.56 \pm 0.09^{\mathrm{cd}}$ \\
\hline
\end{tabular}

Values represent mean \pm standard deviation $(n=5)$. Values followed by the same letter under the same row, are not significantly different $(p>0.05)$. Oil yield was expressed in $\mathrm{ml} / 100 \mathrm{~g}$ dry matter. DPPH radical-scavenging activity (\%) was determined for essential oil concentration at $1 \mathrm{mg} / \mathrm{ml}$. Metal $\left(\mathrm{Fe}^{2+}\right)$ chelating activity was presented as $\mathrm{IC}_{50}$ values $(\mathrm{mg} / \mathrm{ml})$. Coding numbers of altitudinal populations: see Table 1 .

the phase of the plant development induce high variations on yield and chemical composition of essential oils according to the plant species (Rahimmalek et al. 2009; Zouari et al. 2012).

After that, essential oils were subjected to screening for their metal $\left(\mathrm{Fe}^{2+}\right)$ chelating and DPPH radical-scavenging activities (Table 3). Results of the present study confirmed that $A$. herba-alba essential oils were not able to reduce effectively the stable free radical DPPH as compared to the synthetic antioxidant BHA. In fact, DPPH radicalscavenging activity of essential oils at $1 \mathrm{mg} / \mathrm{ml}$ were lower than $15.46 \%$ as was found previously for other Artemisia species essential oils (Lopes-Lutz et al. 2008), whereas the $\mathrm{IC}_{50}$ value of the synthetic antioxidant BHA was $13 \mu \mathrm{g} / \mathrm{ml}$. Metal chelating activity was known as one of antioxidant mechanisms, since it reduced the concentration of the catalyzing transition metal in lipid peroxidation. Among the transition metals, $\mathrm{Fe}^{2+}$ ion was known as the most important lipid oxidation prooxidant due to its high reactivity (Liu et al. 2007). Results showed that statistically significant differences of chelating activity were affected by the population altitude. In fact, the highest chelating activity $\left(\mathrm{IC}_{50}\right.$ value $=0.14 \mathrm{mg} / \mathrm{ml}$ ) was found in population 3 located at $219 \mathrm{~m}$. Although the chemical EDTA $\left(\mathrm{IC}_{50}\right.$ value $=40 \mu \mathrm{g} /$ $\mathrm{ml})$ presented the highest chelating activity, natural compounds were of growing interest as compared with synthetic ones.

\section{Influence of population altitude on antimicrobial activities of essential oils}

The antimicrobial activities of $A$. herba-alba essential oils against six species of microorganisms was assessed by the determination of minimum inhibitory concentrations (MICs) values ( $\mathrm{mg}$ of oil $/ \mathrm{ml}$ of medium). As it can be seen from Figure 3, A. herba-alba essential oils showed varying

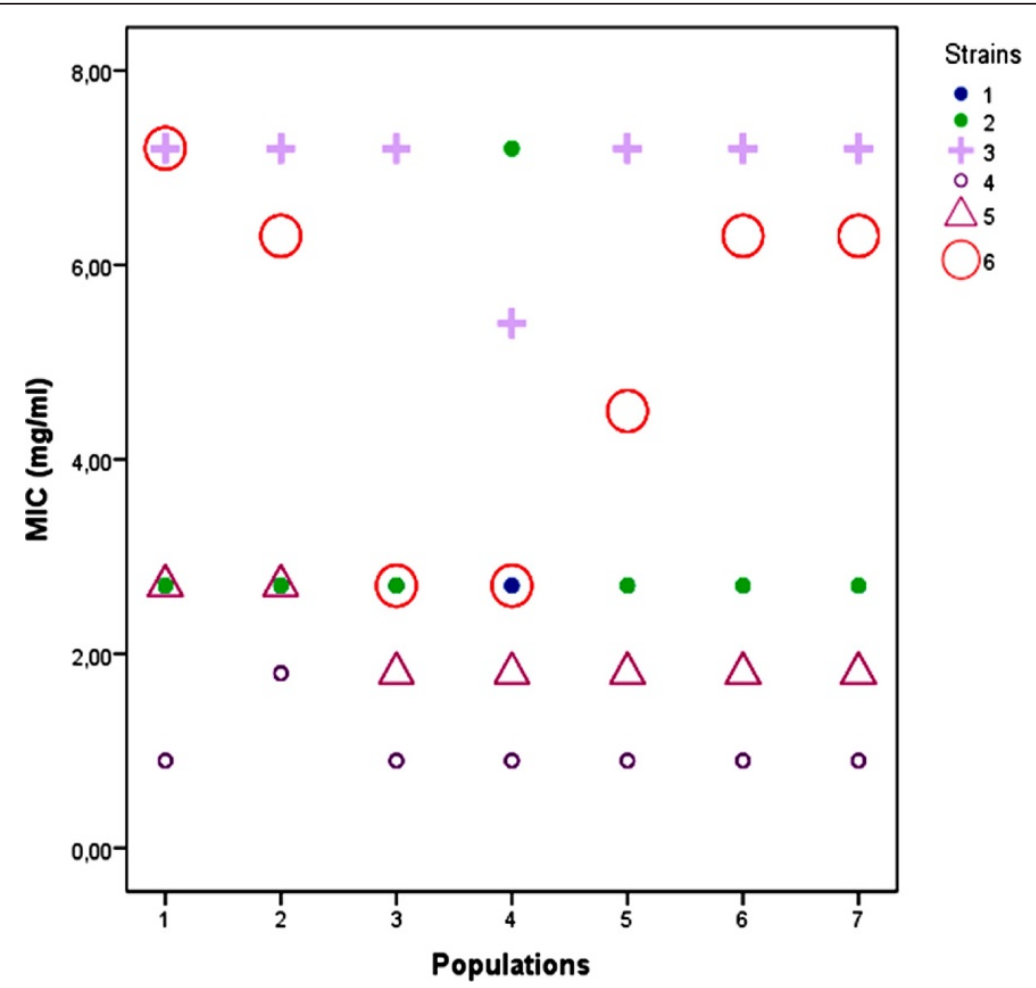

Figure 3 Distribution of minimum inhibitory concentrations (MIC, $\mathrm{mg} / \mathrm{ml}$ ) of essential oils from altitudinal A. herba-alba populations against six bacterial strains. The analyzed strains were: 1: Klebsiella pneumoniae, 2: Escherichia coli, 3: Salmonella typhimurium, 4: Enterococcus faecalis, 5: Bacillus pumulis, and 6: Micrococcus luteus. Coding numbers of altitudinal populations: see Table 1. 
degrees of antimicrobial activities against all strains tested. In fact, the highest bacteriostatic activity was observed against E. faecalis (MIC=0.9-1.8 $\mathrm{mg} / \mathrm{ml})$. However, $S$. typhimurium showed the less sensitivity (MIC of about $7 \mathrm{mg} / \mathrm{ml}$ ). The determination of the correlation between the populations' altitudes and all the measured MICs values (general model) showed no significant correlation $(\mathrm{r}=-$ $0.4, p=0.57)$. Nevertheless, regression analysis showed that altitude variation was significantly correlated $(\mathrm{r}=0.77)$ with MICs values of $M$. luteus following a cubic model (data not shown). The antimicrobial activity of $A$. herbaalba essential oils might be related to their oxygenated monoterpenes compounds which constituted about (52.1$72.6 \%$ ) of the total oil as was previously suggested (Cox et al. 2000; Lopes-Lutz et al. 2008). In fact, it was shown that monoterpenes in essential oils are able to affect cellular integrity resulting in alteration in permeability of microbial cell and mitochondria membranes. Essential oils are also able to inhibit the synthesis of DNA, RNA, proteins, and polysaccharides in bacterial cells (José Abad et al. 2012). Previous works focusing on the antimicrobial activities of different Artemisia essential oils tried to correlate these activities to one or many major compounds. However, it is difficult to attribute the antibacterial activity of a complex mixture to a particular compound. In fact, minor compounds as well as compounds with synergistic or antagonistic effects may play an important role in modulating the antibacterial activity of the entire essential oil. In this way, an essential oil is defined not only by its major compounds, but rather by a majority of all its compounds (Zouari 2013).

\section{Conclusions}

A. saharae oils were extracted by hydrodistillation of leaves and flowers of the plant collected from seven different altitudes of the Baten Zamour region (southwest of Tunisia). The highest essential oil yields $(2.70-2.80 \%)$ were obtained for populations of high altitudes. Sabinyl acetate which was detected in some populations at relatively high percentages (7.7-10.8\%) seems to be characteristic to Southern Tunisian A. saharae. Three population groups associated with altitudinal levels were distinguished. It is worthy to note that the most discriminating compounds of chemical groups were the minor ones. Based on the determination of the minimum inhibitory concentration, a low to a moderate antimicrobial activity according to oils was revealed against six bacteria tested. No significant correlation of antimicrobial activity and altitude variation was observed. Despite A. saharae oils were not able to reduce effectively the stable free radical DPPH, they showed relatively important metal $\left(\mathrm{Fe}^{2+}\right)$ chelating activity. Altitude seems to be an important factor influencing the yield and the chemical profile of Artemisia saharae essential oils, which can be used as a criterion for selection harvesting area by relevant industries.

\section{Competing interests}

The authors declare that they have no competing interests.

\section{Authors' contributions}

SZ, MK and LA (chemists) carried out plant collection, hydrodistillation and chemical composition analysis of essential oils. IA and AR (statisticians) contribute to the statistical analyses. NF and HR (microbiologists) realized biological activities of essential oils. NZ (biochemist) participated in the study design and the redaction of the manuscript. Authors read and approved the final manuscript.

\section{Acknowledgement}

Special thanks go to Miss Amina Gammoudi (ISBAM) for her kind help with English. We acknowledge Mr Slah Zaidi (IRA) for his technical assistance during volatiles analysis.

\section{Author details}

'Laboratoire de Chimie Appliqué: Hétérocycles, Corps gras et Polymères, Faculté des Sciences de Sfax, Université de Sfax, B.P. 11713000 Sfax, Tunisia. 'Laboratoire de Microorganismes et de Biomolécules, Equipe de criblage moléculaire et cellulaire, Centre de Biotechnologie de Sfax, B.P. 1177, 3018 Sfax, Tunisia. Institut Supérieur de Biologie Appliquée de Médenine, Université de Gabès, 4119 Médenine, Tunisia. ${ }^{4}$ Laboratoire de Biochime et de Génie Enzymatique des Lipases, Université de Sfax, Ecole Nationale d'Ingénieurs de Sfax, B.P. 11733038 Sfax, Tunisia.

Received: 30 August 2014 Accepted: 21 November 2014 Published online: 10 December 2014

\section{References}

Adams RP (2001) Identification of essential oil components by gas chromatography/quadrupole mass spectrometry. Allured Publishing Corporation, Carol Stream USA

Avci AB (2011) Chemical variation on the essential oil of Thymus praecox ssp. scorpilii var. Laniger. Int J Agric Biol 13:607-610

Belhattab R, Amor L, Barroso JG, Pedro LG, Figueiredo AC (2014) Essential oil from Artemisia herba-alba Asso grown wild in Algeria: Variability assessment and comparison with an updated literature survey. Arab J Chem 7:243-251

Ben Bnina E, Hammami S, Daami-Remadi M, Cheraif I, Hajjlaoui H, Ben Jannet H, Ben Said M, Mighri Z (2009) Composition and antimicrobial activities of essential oils from the aerial parts and flowers of Thymus hirtus W. growing in Tunisia. J Essent Oil Res 21:567-572

Boukrich F, Zouari S, Neffati M, Abdelly C, Liu K, Casanova J, Tomi F (2010) Chemical variability of Artemisia herba-alba Asso growing wild in semi-arid and arid land (Tunisia). J Essent Oil Res 22:331-335

Cox SD, Mann CM, Markham JL, Bell HC, Gustafson JE, Warmington JR, Wyllie SG (2000) The mode of antimicrobial action of the essential oil of Melaleuca alternifolia (tea tree oil). J Appl Microbiol 88:170-175

Dinis TC, Maderia VM, Almeida LM (1994) Action of phenolic derivatives (acetaminophen, salicylate, and 5-aminosalicylate) as inhibitors of membrane lipid peroxidation and as peroxyl radical scavengers. Arch Biochem Biophys 315:161-169

Haider F, Kumar N, Banejee S, Naqvi AA, Bagchi GD (2009) Effect of altitude on the essential oil constituents of Artemisia roxburghiana Besser var. purpurascens (Jacq.) Hook. J Essent Oil Res 21:303-304

Haider F, Kumar N, Naqvi AA, Bagchi GD (2010) Oil constituents of Artemisia nilagirica var. septentrionalis growing at different altitudes. Nat Prod Commun 5:1959-1960

Haouari M, Ferchichi A (2009) Essential oil composition of Artemisia herba-alba from Southern Tunisia. Molecules 14:1585-1594

Hatimi S, Boudouma M, Bichichi M, Chaib N, Idrissi NG (2001) Evaluation in vitro de l'activité antileishmanienne d'Artemisia herba-alba Asso. Bull Soc Pathol Exot 94:29-31

José Abad M, Bedoya LM, Apaza L, Bermejo P (2012) The Artemisia L. Genus: A Review of Bioactive Essential Oils. Molecules 17:2542-2566

Kirby AJ, Schmidt RJ (1997) The antioxidant activity of Chinese herbs for eczema and placebo herbs. J Ethnopharmacol 56:103-108

Kofidis G, Bosabalidis A, Moustakas M (2003) Contemporary seasonal and altitudinal variations of leaf structural features in oregano (Origanum vulgare L.). Ann Bot 92:635-645 
Kovàts E (1958) Characterization of organic compounds by gas chromatography. Part 1. Retention indices of aliphatic halides, alcohols, aldehydes and ketones. Helv Chim Acta 41:1915-1932

Le Floc'h E, Boulos L, Vela E (2010) Catalogue synonymique commenté de la flore de Tunisie. Ministère de l'Environnement et du Développement durable - Banque Nationale de Gènes, Montpellier, Tunis

Liu L, Song G, Hu Y (2007) GC/MS Analysis of the essential oils of Piper nigrum L. and Piper longum L. Chromatographia 66:785-790

Lopes-Lutz D, Alviano DS, Alviano CS, Kolodziejczyk PP (2008) Screening of chemical composition, antimicrobial and antioxidant activities of Artemisia essential oils. Phytochemistry 69:1732-1738

Mighri H, Akrout A, El-Jeni H, Zaidi S, Tomi F, Casanova J, Neffati M (2010) Composition and intraspecific chemical variability of the essential oil of Artemisia herba-alba growing wild in Tunisian arid zone. Chem Biodivers 7:2709-2717

Rahimmalek M, Tabatabaei BES, Etemadi N, Goli SAH, Arzani A, Zeinali H (2009) Essential oil variation among and within six Achillea species transferred from different ecological regions in Iran to the field conditions. Indust Crop Prod 29:348-355

Tahraoui A, El-Hilaly J, Israili ZH, Lyoussi B (2007) Ethnopharmacological survey of plants used in the traditional treatment of hypertension and diabetes in south-eastern Morocco (Errachidia province). J Ethnopharmacol 110:105-117

Yashphie J, Feuerstein I, Barel S, Segal R (1987) The antibacterial and antispasmodic activity of Artemisia herba-alba Asso. II Examination of essential oils from various chemotypes. Int J Crude Drug Res 25:89-96

Zouari N (2013) Essential oils: A less known side. Med Aromat Plants 1:e145, doi:10.4172/2167-0412.1000e145

Zouari S, Zouari N, Fakhfakh N, Bougatef A, Ayadi MA, Neffati M (2010) Chemical composition and biological activities of a new essential oil chemotype of Tunisian Artemisia herba alba Asso. J Med Plants Res 4:871-880

Zouari N, Ayadi I, Fakhfakh N, Rebai A, Zouari S (2012) Variation of chemical composition of essential oils in wild populations of Thymus algeriensis Boiss. et Reut., a North African endemic Species. Lipids Health Dis 11:28

doi:10.1186/s40529-014-0076-0

Cite this article as: Zouari et al:: Essential oil variation in wild

populations of Artemisia saharae (Asteraceae) from Tunisia: chemical composition, antibacterial and antioxidant properties. Botanical Studies $201455: 76$

\section{Submit your manuscript to a SpringerOpen ${ }^{\circ}$ journal and benefit from:}

- Convenient online submission

- Rigorous peer review

- Immediate publication on acceptance

- Open access: articles freely available online

- High visibility within the field

- Retaining the copyright to your article

Submit your next manuscript at $\gg$ springeropen.com 